\title{
Improving protection for Ebola workers
}

A

s Ebola continues to spread, complaints about the hot and cumbersome personal protective equipment are finally being addressed.

In West Africa, most international volunteers wear the ubiquitous yellow suit made by DuPont out of a material called Tychem, which is "really, really unbreathable," says Dr. Robert Fowler, of the World Health Organization's Department of Pandemic and Epidemic Disease and Toronto's Sunnybrook Hospital.

In West Africa, temperatures inside the suit routinely reached 46 degrees. "And people get really dehydrated the humidity's so high that ... you sweat to the point that water's just everywhere inside the suit." This forces health care workers to change every hour, severely limiting the time they spend with patients and increasing the risk of infection each time they disrobe.

Complaints about the Tychem suit reached the United States Agency for International Development (USAID). In September, President Barack Obama launched Fighting Ebola: A Grand Challenge for Development, to trigger proposals for better personal protective equipment (PPE), and USAID held a brainstorming session for engineers and others in the PPE manufacturing community.

The two-month challenge relied on a \$5-million traditional grant competition, combined with a novel Facebook-like platform where anyone could participate in generating - or commenting on - ideas. USAID received more than 1500 proposals through the two routes, which "really blows the top off of anything we've ever done at USAID in terms of the kind of response rate," says Wendy Taylor, director of the agency's Center for Accelerating Innovation, who worked with others to cull the list.

In November, 25 groups pitched their products to a Dragon's Den-like panel of government experts. Next, the

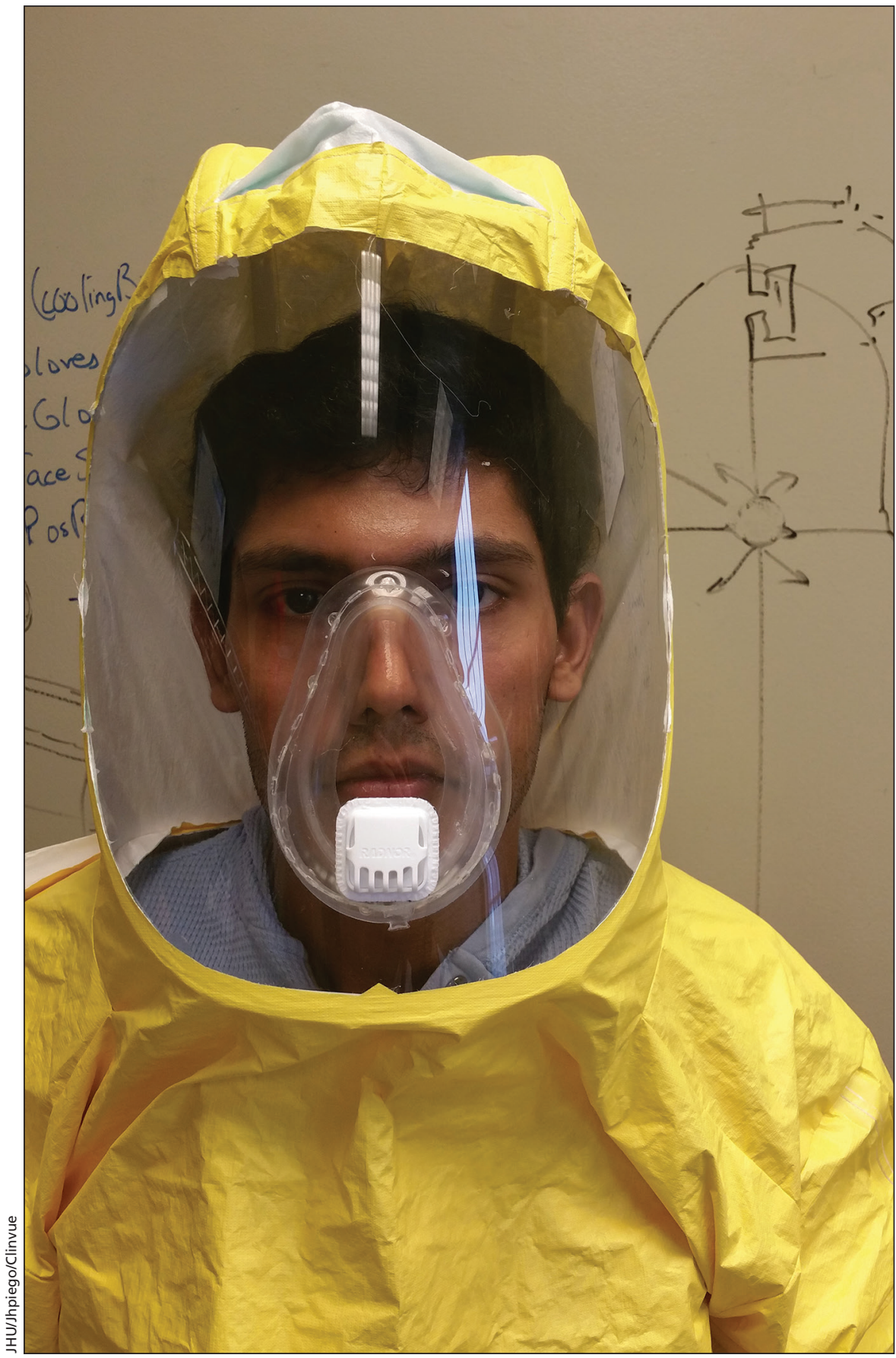

A suit developed by Johns Hopkins University researchers has a fan that blows in dry air to alleviate heat and humidity, plus a larger viewing area and better defogging system.

agency invited "a handful of the innovators" to provide concept notes, and on Dec. 12 announced the first winners: a group at Johns Hopkins University will make a suit that cools the wearer through a device that blows dry air into the hood; a company in Boston will test a coating that results in an electrically charged surface intended to kill the virus on contact; and a California 
company will test an antiseptic lotion that is supposed to decrease the chance of becoming infected when changing out of a PPE suit.

\section{Off-the-shelf approach}

At Ohio-based Lion Apparel, which supplies protective equipment to police and firefighters in several countries, CEO Steve Schwartz thinks there's a quicker fix: off-the-shelf products such as his company's Extended Response Suit that are already available and tested against set standards.

"It's going to be more comfortable because it's breathable," he says, adding that it includes integrated gloves sewn into the sleeve and built-in closure systems, as opposed to a health care worker having to tape the cuffs and ankles. It has not been trialled in West Africa, and Lion's proposals to the Grand Challenge did not lead to an invitation to go further, but other off-the-shelf products did get a nod. USAID is evaluating several wearable cooling products, including a vest with ice packs used by the military, and a Virginia company's cooling packs inserted in compression shorts, and hoping "to get the best ideas into the field in the next month," says Amy Garrett, USAID's deputy press director.

Immunologist David Kelvin of the Toronto General Research Institute warns that better PPE suits are needed before trials of experimental vaccines start up among health care workers in Ebola treatment units. "The danger is that people will see the vaccine as a false sense of security," he says. Com- bined with the intense discomfort of current PPE, that's a problem: there could be "some additional infections, because people won't pay as close attention to their PPEs."

And vaccine trials are not that far off. The World Health Organization expects phase two trials of one of the four vaccine candidates - a vaccine GlaxoSmithKline is developing with the US National Institutes of Health to begin in February in countries near those affected by Ebola. Phase three trials will follow in Ebola-affected regions later this year. Garrett says USAID hopes to be testing the new suit in several months. - Miriam Shuchman MD, Toronto, Ont.

CMAJ 2015. DOI:10.1503/cmaj.109-4969 